\title{
Tendencias actuales en el matrimonio en China
}

\section{Tendencies in Contemporary Chinese Marriage}

\author{
FLORA BOTTON BEJA*
}

Resumen: El matrimonio, elemento clave de la sociedad china, ha tenido importantes transformaciones desde mediados del siglo pasado. De ser una transacción acordada entre los padres, pasó a depender de la voluntad y la elección de los cónyuges. Estos cambios fueron impulsados desde el Estado mediante las Leyes de Matrimonio de 1950, 1980 y 2001 y han contribuido a alteraciones radicales en la familia y la sociedad. Sin embargo, el matrimonio en China sigue conservando elementos tradicionales. Este artículo estudia las nuevas tendencias en divorcios, derechos conyugales, nuevas formas de encontrar pareja e incluso la incipiente discusión sobre matrimonios homosexuales en ese país.

Palabras clave: China; matrimonio; familia; divorcio; mujeres.

Abstract: Marriage, a key element of Chinese society, has experienced a great transformation since the mid-twentieth century. From being a transaction arranged by the parents, it is now viewed as a choice based upon the free will of both partners. This change has been promoted by the state through the marriage laws of 1950, 1980 and 2001, which have contributed towards radical shifts in family and society. Nevertheless, traditional principles still influence marriage in China. This paper studies recent trends in marriage in contemporary China including thoughts about divorce, conjugal rights, new

Recepción: 19 de enero de 2017. / Aceptación: 7 de abril de 2017.

* El Colegio de México, botton@colmex.mx 
ways of meeting partners and the emerging public discussion on samesex marriage.

Key words: China; marriage; family; divorce; women.

La transformación de China después de las reformas económicas de 1978 ha sorprendido al mundo y ha sido tema de numerosas investigaciones, pero también es importante estudiar el efecto que tuvieron estas reformas en la población, sobre todo en la familia, institución fundamental dentro de la sociedad china que había sufrido grandes cambios después del triunfo de la Revolución de 1949, pero conservaba aún muchas de sus características tradicionales. ¿Hasta qué punto las relaciones familiares se han transformado en esta rápida modernización? ${ }^{1}$ ¿Hasta qué punto la modernización ha afectado el matrimonio, que fue y sigue siendo la única manera aceptable de formar una familia? En la actualidad hay muchos estudios que, con métodos sociológicos, antropológicos y demográficos, tratan de contestar esta pregunta.

\section{El matrimonio en la China tradicional}

El matrimonio en la China tradicional reunía las características señaladas por los antropólogos para la mayoría de las sociedades y constituía tanto un intercambio de mujeres con el fin de forjar alianzas y consolidar grupos de poder (Levi-Strauss), como un medio de asegurar la descendencia. En China se conjugaron, además, elementos de orden económico, ideológico y religioso para hacer del matrimonio el elemento clave de una sociedad estable. Para los chinos era el rito que, desde épocas muy antiguas, garantizaba la pertenencia a una sociedad civiliza$\mathrm{da}$, en contraste con grupos "bárbaros" en los que un individuo a veces no sabía quién era su padre. Los textos clásicos son muy precisos cuando hablan del matrimonio y su importancia. Dice el Li Ji: "La ceremonia de matrimonio es un vínculo de

${ }^{1}$ Este aspecto ha sido estudiado en Flora Botton, “Algunas consideraciones sobre las relaciones intrafamiliares y las redes de apoyo en la China actual”, Estudios de Asia y África, vol. 51, núm. 3 (161), septiembre-diciembre de 2016, pp. 511-530. 
afecto entre dos [familias de] diferentes apellidos a fin de, por un lado, asegurar los servicios en el templo ancestral y, por el otro, asegurar la continuidad de la línea familiar". ${ }^{2}$ Y el Bobutong afirma: “¿Por qué es importante el matrimonio? Porque entre todos los sentimientos e instintos no hay ninguno más importante que los que aparecen entre hombre y mujer. En la relación entre hombre y mujer, en tanto que son el principio de las relaciones humanas, no hay nada [más importante] que la relación de esposo y esposa". ${ }^{3}$ La concertación y arreglo del matrimonio era una tarea que correspondía a los jefes de familia, sin tomar en consideración la inclinación de los contrayentes. "¿Por qué un hombre no puede casarse por su propia iniciativa ni tampoco puede hacerlo una mujer y [para ambos] el matrimonio es decisión de los padres y debe ser arreglado por un intermediario? Es para alejar la vergüenza y evitar la promiscuidad". ${ }^{4}$ A pesar de ciertos movimientos liberalizadores a partir de la Revolución de 1911, se puede decir que, hasta el establecimiento de la República Popular en 1949, la gran mayoría de los chinos se casaba sin conocerse hasta el día de su boda. ${ }^{5}$ Tampoco hay que olvidar que, al contraer matrimonio, la familia del novio debía dar a la de la novia una dote que, entre la gente rica, era muy abundante, y entre los pobres podía consistir en un saco de arroz. Esto hacía que la esposa fuera considerada como una propiedad de la familia del esposo, ya que de alguna manera la había comprado.

A pesar de que ambos contrayentes estaban sujetos a las mismas reglas en cuanto al arreglo de su matrimonio, después de casados se establecía inmediatamente una jerarquía entre los cónyuges. Según el Bohutong, "la razón por la cual [aun] cuando el marido se porta mal, la esposa no tiene derecho de dejarlo, se encuentra en el principio de que la Tierra no

${ }^{2}$ The Li Ki, tr. James Legge, en F. Max Müller (ed.), The Sacred Books of the East, vol. 28, Delhi, Motilal Banarsidass, 1966, p. 428 (publicado anteriormente por Claredon Press, 1885).

${ }^{3}$ Po Hu T'ung, The Complete Discussions with the White Tiger Hall, intr. y tr. Tjan Tjoe Som, Leiden-Boston, E. J. Brill, 1952, vol. 1, p. 244.

${ }^{4}$ Ibid., p. 251.

${ }^{5}$ Flora Botton y Romer Cornejo, "Corazones solitarios: los anuncios matrimoniales y la elección de pareja en China”, Estudios de Asia y África, vol. 25, núm. 1 (81), enero-abril de 1990, p. 84. 
se separa del Cielo". ${ }^{6}$ En la familia tradicional, patriarcal, la posición de las mujeres era inferior a la de los varones porque los hijos permanecían en la familia y contribuían a la economía familiar, mientras que las hijas eran miembros no permanentes que abandonaban el hogar paterno al casarse. De este modo, no había ningún incentivo para educar a las mujeres, y esta situación las volvía aún más vulnerables y sujetas a la voluntad de los varones de la familia. ${ }^{7}$

\section{Cambios a partir de 1949}

Al triunfar la Revolución en 1949, los dirigentes del Partido Comunista estaban conscientes de que no bastaba con modificar el sistema político y económico para que hubiera un cambio social en China; era necesario cambiar las bases mismas de la organización familiar, es decir, las relaciones entre los individuos que la constituyen y dirigir la lealtad de sus miembros hacia el Estado. Así fue como se dieron a la tarea de promulgar leyes que transformarían las relaciones familiares. La reforma que más impactó a la familia fue, sin duda alguna, la proclamación de la Ley de Matrimonio en 1950, en la que se reconoce a la familia como una unidad formada por una pareja y sus hijos. El matrimonio es un contrato basado en el afecto y el consentimiento, que se realiza entre iguales sin interferencia de terceros. Hay cláusulas específicas que prohíben los matrimonios arreglados, la concertación de compromisos entre niños, la poligamia y el pago por una novia, todo ello parte de las costumbres tradicionales. El divorcio puede ser solicitado por cualquiera de las partes y hay cláusulas que protegen a mujeres y niños. Esta nueva ley tuvo repercusiones en todos los ámbitos de la sociedad. Al quitar al jefe de familia el derecho de concertar el matrimonio de sus hijos, se privó al patriarca de uno de sus mayores poderes, lo que cambió la relación

${ }^{6}$ Po Hu T'ung, The Complete Discussions..., op. cit., p. 251.

${ }^{7} \mathrm{Xu}$ Qi, Jianxin Li y Xuejun Yu, "Continuity and Change in Chinese Marriage and the Family: Evidence from the CFPs”, Chinese Sociological Review, vol. 47, núm. 1, 2014, pp. 49-50; Flora Botton y Romer Cornejo, Bajo un mismo techo. La familia tradicional en China y sus cambios, México, El Colegio de México, 1993, pp. 42 y passim. 
jerárquica dentro de la familia. La pareja se volvió central en una relación de igualdad reforzada por la incorporación de las mujeres al trabajo productivo. Si bien no todo cambió de la noche a la mañana, la nueva ley ayudó a que los jóvenes y las mujeres pudieran liberarse de la opresión a la cual habían estado sujetos. ${ }^{8}$ La libertad de contraer matrimonio, además de la incorporación de la mujer a la fuerza laboral, afectaron la posición del patriarca y cambiaron las relaciones de poder, elevaron la posición de la mujer y establecieron bases diferentes para la estructura familiar, lo que le dio un papel central a la pareja. ${ }^{9}$

En 1980, la Ley de Matrimonio fue revisada y modificada para responder a exigencias de nuevos desarrollos en el sistema legal y para adecuarla a la modernización incipiente. La nueva ley, que entró en vigor el 1 de enero de 1981, reiteró los principios ya expresados en la de 1950 acerca de las relaciones entre los miembros de la familia: monogamia, igualdad de género, matrimonio consensual. Sin embargo, los cambios más significativos fueron los que se hicieron a la luz de la nueva política demográfica. Por un lado, se aumentó la edad mínima de casamiento de 20 a 22 años para los hombres y de 18 a 22 para las mujeres (artículo 5). El control de la natalidad se convirtió en un deber legal para hombres y mujeres (artículo 12) y se incentivó el casamiento y los embarazos tardíos (artículo 5). ${ }^{10}$

En los primeros 20 o 25 años de vida de la República Popular China, la liberación de los miembros más vulnerables de la familia tuvo nuevas restricciones, esta vez por parte del Estado. El matrimonio estaba ciertamente libre de interferencias familiares, pero al ser necesario su registro, había un control que muchas veces resultaba en el impedimento para efectuarlo. La pareja necesitaba tener el permiso del responsable político de su unidad de trabajo, y ya fuera por razones políticas, antipatía personal u otros intereses, no lo obtenían.

${ }^{8}$ Flora Botton, "La larga marcha hacia la igualdad. Mujer y familia en China", en Taciana Fisac (ed.), Mujeres en China, Madrid, Agencia Española de Cooperación Internacional, 1995, p. 32.

${ }^{9}$ Botton y Cornejo, “Corazones solitarios”, op. cit., p. 84.

${ }^{10}$ Harriet Evans, “Matrimonio y familia en China”, Revista FEM, vol. 7, núm. 22, abril-mayo de 1982, pp. 5-10. 
Esta situación se agudizó durante la Revolución Cultural hasta llegar al extremo, a veces, de obligar a un miembro de la pareja a divorciarse si las autoridades lo consideraban políticamente no grato. Con frecuencia se separaba a las parejas asignándoles trabajos en lugares apartados sin posibilidad de verse más que una vez al año. La distribución de vivienda era otra manera de atrasar o impedir un matrimonio, puesto que la unidad de trabajo era la que la asignaba. Asimismo, al intensificarse las campañas de planificación familiar, la edad mínima para contraer matrimonio aumentó, lo que, debido a la actitud puritana de la sociedad en aquella época, significaba también retrasar la sexualidad de los jóvenes. ${ }^{11}$

Las leyes de 1950 y 1980 tuvieron un papel importante en el fomento del matrimonio socialista, afirmando algunos derechos individuales y contribuyendo a la estabilidad en la familia y la sociedad. Sin embargo, carecían de estipulaciones sobre los requisitos de un matrimonio formal, las relaciones entre individuos, la división de la propiedad, la custodia de los hijos y otros asuntos pertinentes al matrimonio. ${ }^{12}$

La transición a la economía de mercado y la apertura de China al mundo, que significaba adquirir nuevos compromisos internacionales (firma de tratados o acuerdos sobre mujeres, niños, no discriminación, etcétera), además de los viejos problemas no resueltos y los nuevos, surgidos de los cambios en la sociedad china, hacían necesaria una actualización de la Ley de Matrimonio. El aumento de divorcios, la violencia doméstica (causa de 60\% de los divorcios), las relaciones extramaritales ( $20 \%$ de los hombres casados admitió tener relaciones extramaritales), el abandono de los ancianos por la pérdida de valores tradicionales de respeto y obligación hacia los padres, así como los problemas de propiedad conyugal antes inexistentes,

${ }^{11}$ Flora Botton, “La sociedad china contemporánea: una visión actual”, en José Luis Estrada, José Luis León y Ricardo Buzo (coords.), China en el siglo XXI. Economía, política y sociedad de una potencia emergente, México, Universidad Autónoma Metropolitana, 2006, p. 50.

${ }_{12}$ Zhang Xuejun, "Amendment of the Marriage Law in China", International Journal of Law, Policy and the Family, vol. 16, núm. 3, 1 de diciembre de 2002, pp. 399409; William P. Alford y Shen Yuanyuan, "Have you eaten? Have you divorced? Debating the Meaning of Freedom in Marriage in China", en William Kirby (ed.), Ideas of Freedom in the Chinese World, Stanford, Stanford University Press, 2003, pp. 7-8. 
necesitaban de una solución. ${ }^{13}$ La nueva ley, promulgada el 28 de abril de 2001, significó cinco años de trabajo intenso de un comité de la comisión permanente de la Asamblea Nacional Popular, que organizó debates con abogados, psicólogos y trabajadores sociales, y llevó a cabo consultas populares en las que hubo una gran participación. Se recibieron unas 40000 cartas en las que los ciudadanos opinaban sobre la nueva ley. En ella se precisan las normas que rigen un matrimonio legal, como la necesidad de registro que permite al Estado controlar la edad del matrimonio, evitar casos de bigamia, reglamentar la nulidad del matrimonio o la reparación del daño, etcétera. ${ }^{14} \mathrm{Se}$ legisló sobre bigamia, matrimonio forzado, relaciones extramaritales, violencia doméstica - antes considerada como asunto intrafamiliar-, y se señalaron las consecuencias ante la ley en caso de incurrir en irregularidades. Las causas de divorcio se enumeraron e incluyen bigamia, adulterio y violencia. Además, hay estipulaciones sobre patria potestad, manutención y reglas de visitas de los niños de parejas divorciadas. La protección a niños y ancianos y la obligación de mantenerlos se hace más clara y más precisa. Hay también una cláusula sobre el derecho de los padres ancianos de volver a casarse. ${ }^{15}$ Es bien sabido que en la China tradicional, y aun en la posrevolucionaria, los padres ejercían gran control e interferían en el matrimonio de sus hijos. En épocas más recientes, son los hijos los que a veces se oponen cuando sus padres desean volver a contraer matrimonio. Por eso, en el artículo 30 de la Ley de Matrimonio de 2001 también se dice: "los hijos respetarán el derecho de los padres de casarse y no interferirán en el matrimonio de los padres"; sin embargo, los hijos siguen siendo responsables del mantenimiento de sus padres "sin importar cualquier cambio en su estado civil". ${ }^{16}$

${ }^{13}$ Susan Lawrence, "Divorce, Chinese Style", Far Eastern Economic Review, vol. 164, núm. 11, 15 de marzo de 2001, pp. 64-66; Olga Pochagina, "New Version of the PRC Law on Marriage", Far Eastern Affairs, vol. 30, núm. 4, octubre-diciembre de 2002, pp. 29-30.

${ }^{14}$ Michael Palmer, "Transforming Family Law in post-Deng China: Marriage, Divorce and Reproduction”, The China Quarterly, vol. 191, septiembre de 2007, p. 678.

${ }^{15}$ Zhang, "Amendment of the Marriage Law in China", op. cit., pp. 10-11. Botton, "La sociedad china contemporánea”, op. cit., pp. 41 y passim.

${ }^{16}$ Zhang, "Amendment of the Marriage Law in China", op. cit., p. 406; Palmer, “Transforming Family Law in post-Deng China”, op. cit., p. 681. 


\section{Elección de pareja}

El triunfo del socialismo en 1949 y la Ley de Matrimonio de 1950 le dieron al individuo la libertad de elección de compañero/a, al mismo tiempo que le cedían al partido y al Estado la responsabilidad de guiar a los jóvenes en la realización de esta elección, con lo que se remplazó a la familia en la definición de criterios para establecer una relación. Muy pronto, junto al trabajo de propaganda en la base que se desarrolló en todo el país, hubo folletos, artículos y editoriales de periódicos que trataban el problema del amor y el matrimonio. Hasta finales de los años setenta se puede rastrear una continua repetición de ciertos consejos y criterios básicos sobre la cuestión del amor. ${ }^{17}$

¿Cuáles son las principales razones de este interés del Estado en un asunto que en otros países sería discutido, en el mejor de los casos, entre ciertos grupos religiosos o en revistas femeninas? En primer lugar, la falta de experiencia en tales asuntos por parte de una población que no había tenido oportunidad de casarse por inclinación personal fue percibida como un peligro. La libertad de elección podía conducir a pasiones desenfrenadas en nombre de la libertad, y la vena romántica que se había insinuado a principios de los años veinte podía convertirse en la norma. ${ }^{18}$ Puesto que el individuo tiene la responsabilidad de participar en la meta principal de la Revolución, y dado que el correcto manejo de sus asuntos amorosos puede influir en esta meta final, compete al Estado definir los límites de la libertad de amar y de elegir a quién se ama. Enamorarse no es ceder a un impulso, no es responder a una atracción irracional. En todos los escritos de los años cincuenta y sesenta se reconoce que la inclinación natural es sentirse atraídos por la belleza física, el carácter, la posición, el dinero, la educación. Éstas son valoraciones que la mayoría de la gente reconoce. Sin embargo, el criterio fundamental recomendado para amar a otra persona es la compatibilidad política. ${ }^{19}$

${ }^{17}$ Flora Botton, "El amor es cosa seria: el discurso oficial sobre el amor en China (1949-1979)”, Estudios de Asia y África, vol. 29, núm. 3 (95), septiembre-diciembre de 1994 , p. 390.

${ }^{18}$ Idem.

${ }^{19}$ Ibid., p. 396. 
A pesar de que la libre elección de la pareja era un derecho en la nueva sociedad, aún no se establecían los mecanismos para que así fuera. En una sociedad donde la separación de los sexos era tradicional, donde no había oportunidades para que la gente joven interactuara -salvo en la universidad, a la que acudían unos cuantos, o en los lugares de trabajo, que frecuentemente eran determinados por el género-, donde la casamentera había tenido en el pasado un papel primordial para arreglar matrimonios, encontrar pareja no era fácil. Finalmente, la edad que estipulaba el gobierno como ideal para el matrimonio, y antes de la cual no era aceptable casarse, dejaba un margen temporal estrecho para conseguir pareja. Como se observa en un documento publicado en 1964, se consideraban viables varias alternativas: "En general, es mejor que los jóvenes encuentren por sí mismos a sus amados. Sin embargo, algunas personas, debido a varios impedimentos, tienen que recurrir a otros para que les presenten a una pareja. Esto no está mal”. ${ }^{20}$ Lo más común durante mucho tiempo fue recurrir a parientes y amigos, pero pronto el gobierno asumió este papel. En los años ochenta, los dirigentes del Partido Comunista instaron a las organizaciones de masas (la Federación de Mujeres, la Liga de la Juventud y los sindicatos) a establecer mecanismos para encontrar pareja. La respuesta de las organizaciones a las cuales iba dirigido el llamado oficial fue inmediata. En 1984, todos los medios de comunicación informaban sobre las actividades que se realizaban para que los jóvenes sin pareja se conocieran. En Shanghái, el Palacio de la Juventud organizó una excursión de solteros a Hangzhou, lugar famoso por su paisaje romántico; la Federación de Mujeres estableció en la ciudad de Beijing seis equipos, llamados "Casamenteros 8 de Marzo", para que idearan actividades adecuadas, como conferencias, conciertos y tés danzantes, y los sindicatos organizaron bailes. Una de las formas que se ha considerado ideal para suplir los viejos métodos de encontrar pareja ha sido la de las agencias matrimoniales. A partir de 1980, comenzaron a surgir oficinas patrocinadas por la Federación de Mujeres, la Liga de la Juventud e incluso

${ }^{20} \mathrm{Lu}$ Yang, "The Correct Handling of Love, Marriage, and Family Problems”, Chinese Sociology and Anthropology, vol. 1, núm. 3, primavera de 1969, p. 20. 
por algunas unidades de trabajo. Finalmente se recurrió a los anuncios en periódicos y revistas. ${ }^{21}$

Aunque el matrimonio sea la norma para la mayoría, no era fácil casarse en China hasta tiempos recientes. Las exigencias en la elección de la pareja eran un tanto rígidas, lo que resulta sorprendente en una sociedad que se quería igualitaria. Para que dos personas se unieran, debían considerarse edad, educación, origen familiar, estatus económico y posición política. Los viejos prejuicios y las diferencias reales impedían que los habitantes de la ciudad se casaran con los del campo, y las trabas burocráticas podían matar con facilidad las pasiones más ardientes. La movilidad espacial estaba estrechamente controlada por reglas de residencia o por las necesidades de las unidades de trabajo, de manera que el traslado de uno de los novios al lugar donde residía el otro era a veces imposible. La poca disponibilidad de vivienda también constituía un factor de gran peso y, como ya se dijo, las oportunidades de conocerse y establecer una relación eran limitadas. Sin embargo, a pesar de las dificultades, la mayoría lograba casarse. Esto se debe a la preocupación de la familia, de los amigos o de los compañeros de trabajo, que adoptaban el papel de casamenteros, y a la voluntad de las autoridades estatales, que establecieron mecanismos de ayuda para formar parejas. También se crearon agencias matrimoniales, y en muchas revistas aparecieron anuncios de personas que buscaban pareja. ${ }^{22}$

Hasta 1990, la mayoría de los chinos quería y lograba casarse. Es cierto que nuevas formas de vida, como mayor libertad de decidir sobre la vida personal, oportunidades de trabajo y de vivienda para gente joven, búsqueda del amor romántico y creciente independencia de las mujeres, tuvieron una influencia negativa en la universalidad del matrimonio; sin embargo, para la mayoría el matrimonio era y sigue siendo la relación más aceptable entre un hombre y una mujer para tener pareja, una vida sexual e hijos. Esta situación está cambiando rápidamente, sobre todo para los hombres, especialmente para los de áreas rurales. Con la disminución de las tasas de nacimiento en China

${ }^{21}$ Botton y Cornejo, “Corazones solitarios”, op. cit., pp. 90-93.

${ }^{22}$ Ibid., pp. 93 y passim. 
desde los años setenta, el índice de masculinidad ha aumentado de modo alarmante..$^{23}$ Las razones son, por un lado, las estrictas políticas de población, con las que el número de nacimientos ha llegado a un nivel inferior al remplazo, pero también la preferencia por tener hijos varones. Tradicionalmente, en China ha habido un déficit de mujeres, porque a las niñas se las descuidaba y se practicaba el infanticidio femenino. Esta selección tiene sus raíces en el papel subordinado que ocupaban las mujeres, su separación de la familia con el matrimonio, su menor valor económico y su falta de oportunidades de educación y desarrollo. Actualmente, con la restricción en el número de hijos que se pueden tener, se hace más urgente tener hijos varones y se han desarrollado estrategias para lograrlo. Según algunos cálculos, entre 2000 y 2021 habrá un excedente de más de 23.5 millones de varones en edad casadera. ${ }^{24}$ Se han realizado algunos estudios sobre las consecuencias de este aumento en varones sin pareja y se señala que puede llevar a frustraciones sexuales y emocionales, además de un aumento en crímenes sexuales, raptos de mujeres, adulterio y homosexualidad. ${ }^{25}$

Una de las razones por las que la escasez de mujeres afecta más a los hombres de áreas rurales, según la investigadora Delia Davin, es la migración por razones matrimoniales. Por un lado, todavía hay vestigios de la tradición china de la exogamia, que hace que las mujeres se casen fuera de su aldea, pero, por el otro, la escasez misma aumenta su valor en el mercado matrimonial y muchas tienen la oportunidad de emigrar hacia regiones más prósperas y casarse con hombres de mejor posición económica y social. Según estadísticas, $30 \%$ de la emigración de mujeres entre provincias en el año 2000 era matrimonial, en contraste

${ }^{23}$ Li Shuzhuo, Zhang Qunlin, Yang Xueyan e Isabelle Attané, "Male Singlehood, Poverty and Sexuality in Rural China: An Exploratory Survey”, Population, vol. 65, núm. 4, 2010, pp. 679-680.

${ }^{24}$ Dudley L. Poston y Karen S. Glover, “Too Many Males: Marriage Market Implications of Gender Imbalances in China”, Genus, vol. 61, núm. 2, abril-junio de 2005, p. 125; Zheng Zhenzhen, "Interventions to balance Sex Ratio at Birth in Rural China”, en Isabelle Attané y Christophe Z. Guilmoto (eds.), Watering the Neighbor's Garden, París, Committee for International Cooperation in National Research in Demography, 2007, pp. 327-328.

${ }^{25}$ Poston y Glover, “Too Many Males”, op. cit., pp. 131-132; Li, Zhang, Yang y Attané, "Male Singlehood...”, op. cit., p. 681. 
con $2 \%$ de la emigración masculina con estas características. ${ }^{26}$ Para algunos investigadores es posible que la situación sea diferente en el futuro debido al cambio de actitud hacia las mujeres que ya es evidente en áreas urbanas y a las restricciones impuestas por el gobierno en cuanto a las pruebas prenatales para determinar el sexo, así como la prohibición de abortos selectivos. $^{27}$

En la actualidad, han proliferado nuevas modalidades para encontrar pareja y hay empresas que acumulan bases de datos y ofrecen servicios bastante onerosos a personas de clase media y alta. A pesar de la mayor facilidad para conocerse y de los distintos mecanismos para relacionarse, el papel de los padres como intermediarios en la tarea de encontrar pareja a sus hijos es aún importante. Un ejemplo es el surgimiento, desde 2004, de mercados de matrimonio, baifaxiangqin, que los padres usan para poner anuncios en lugares públicos, como parques, en los que describen las cualidades de sus hijos o hijas, su edad, estatura, nivel de educación, trabajo y patrimonio. También ponen fotos y hasta el tipo de sangre y el horóscopo. Todo eso a veces $\sin$ el consentimiento de los directamente involucrados. ${ }^{28}$

\section{Divorcio}

Mientras los matrimonios disminuyen en China (en 1998 hubo 8.92 millones de casamientos y en 2003, únicamente 8.11 millones), los divorcios van en aumento, y aunque en comparación con otros países la tasa de divorcios no es tan alta, lo que preocupa es la tendencia al alza: en 2003 hubo 1.33 millones de divorcios, 154000 más que en 2002. En 2014 se registraron 13.07 matrimonios y 2.6 millones de divorcios. ${ }^{29}$ Tanto funcionarios

${ }^{26}$ Delia Davin, "Marriage Migration in China and East Asia", Journal of Contemporary China, vol. 16, núm. 50, marzo de 2007, pp. 84-87 y 91-92.

${ }^{27}$ Zheng, "Interventions to balance Sex Ratio...", op. cit., p. 327 y passim.

${ }^{28}$ Wong Wei Mei, "Finding 'Love' in China: An Overview of Chinese Marriage Markets (BaiFaXiangQin)”, Inquiries Journal, vol. 6, núm. 12, 2014, p. 1; Brook Larmer, "The Price of Marriage in China”, The New York Times, 9 de marzo de 2013.

${ }^{29}$ National Center for Education Statistics, "Number of Divorces in China in 2014, by Region" y "Number of Registered Marriages in China from 2004 to 2014 (in Millions)", Statista. The Statistics Portal, s.f. 
del gobierno como el público en general han reaccionado ante esta situación y han discutido las posibles causas, entre las que está la mayor facilidad tanto para contraer matrimonio como para divorciarse, las tensiones de la vida actual y las mayores oportunidades para entablar una relación extramarital. Si bien para algunas personas esta situación es alarmante, otros opinan que es más sana la actitud actual que permite poner fin a una mala relación.

En el pasado, obtener un divorcio significaba vencer varios obstáculos. Un problema esencial era la vivienda, que al ser asignada por el gobierno o por la unidad de trabajo, dejaba a uno de los cónyuges sin techo. Las parejas que deseaban divorciarse debían pedir el acuerdo de sus lugares de trabajo, y muchas veces se les negaba el permiso y los presionaban para que permanecieran juntos. El divorcio era muy mal visto por la sociedad y se recomendaba tener tolerancia y evitar romper el vínculo, a pesar de existir la causal de rompimiento del vínculo afectivo. Además, una de las causas más importantes de divorcio hoy en día, la infidelidad, no era muy frecuente por razones económicas y por el oprobio que este comportamiento significaba para la parte culpable y que lo alcanzaba hasta el lugar de trabajo. En la actualidad, el problema de la vivienda no es tan agudo, las entidades de trabajo no pueden interferir en la decisión de las parejas y el nivel de tolerancia en una relación problemática o de violencia familiar parece haber bajado, sobre todo en un ambiente en el cual se reciben constantemente mensajes de amor romántico y de pasión que antes no constituían un elemento indispensable en una relación matrimonial. Además, la mayor libertad de los individuos, la disminución del puritanismo revolucionario, la discusión más abierta sobre la sexualidad, las oportunidades de encontrarse en lugares públicos y el reciente enriquecimiento han fomentado las relaciones fuera del matrimonio, lo que ha hecho del adulterio la causa más frecuente de divorcio. Aquí debemos insistir en que esta situación es más habitual en las ciudades, aunque con la difusión que hace la televisión, la tendencia está llegando a las áreas rurales. ${ }^{30}$ La Ley de Matrimonio de 2001 ofrece,

${ }^{30}$ Flora Botton, “Cambio social y cultura”, en Romer Cornejo (coord.), China. 
ciertamente, mayor libertad a la pareja si decide divorciarse y minimiza la intervención estatal. Cuando hay desacuerdo entre las partes, un juicio determina el veredicto. Como ya se ha mencionado, la ley estipula con mucha minuciosidad las causales del divorcio, la nulidad de un matrimonio y, además, prevé la reparación del daño cuando se presenta un caso de dolo de parte de uno de los esposos. ${ }^{31}$

\section{Sexualidad}

El tema de la sexualidad, poco discutido durante la época del puritanismo revolucionario, ya dejó de ser tabú en China. Los medios de comunicación, las revistas, las novelas en las que se describen explícitamente actos sexuales y aun las películas recientes son muestra de la nueva actitud. En la tradición china no existe la idea del pecado original que tanto ha inhibido la sexualidad occidental. En la cosmología antigua se habla de dos fuerzas necesarias y complementarias que son el fundamento del universo, el yin, elemento femenino, y el yang, elemento masculino, y es posible que en épocas muy tempranas estos conceptos tuvieran un valor igual. Para el confucianismo, la sexualidad (dentro del matrimonio) es muy importante. Su finalidad es la procreación para asegurar la descendencia masculina y la continuación de los ritos del culto ancestral. Así es como el confucianismo avala la familia y el matrimonio, pero no necesariamente la actividad sexual como fuente de gozo y felicidad. La virginidad era apreciada en las mujeres, quienes además debían permanecer fieles a sus maridos aun siendo viudas, mientras que ellos podían tomar varias esposas y concubinas. ${ }^{32}$ Después del triunfo de la Revolución en

Radiografía de una potencia en ascenso, México, El Colegio de México, 2008, p. 127 y passim.

${ }^{31}$ Alford y Shen, "Have you eaten? Have you divorced?”, op. cit., p. 13; Palmer, “Transforming Family Law in post-Deng China”, op. cit., p. 694.

32 Botton, "La sociedad china contemporánea", op. cit., pp. 9-10; Zheng Weijun, Xudong Zhou, Chi Zhou, Wei Liu, Lu Li y Therese Hesketh, "Detraditionalisation and Attitudes to Sex Outside Marriage in China”, Culture, Health E Sexuality, vol. 13, núm. 5, mayo de 2011, p. 497. 
1949 se conservaron las estrictas normas sobre sexualidad, y el sexo era visto como una manifestación del individualismo burgués. Tampoco se hablaba mucho de sexualidad, salvo en sus aspectos biológicos. Durante la Revolución Cultural, las manifestaciones exteriores de sexualidad fueron censuradas y la vestimenta era similar para ambos sexos. La sexualidad y la reproducción estaban vinculadas y no había tolerancia para sexo premarital o extramarital. ${ }^{33}$

Desde principios de la década de 1980, los cambios políticos y económicos en China fueron acompañados de transformaciones de índole moral y social. En primer lugar, cambió la actitud hacia el adorno y el vestido. Las mujeres -y también los hombres- comenzaron a elegir ropa más variada en forma y colorido, y se arreglaban el cabello y usaban tacones altos. Los pantalones amplios y poco favorecedores se sustituyeron por faldas y vestidos o pantalones ceñidos y mejor cortados. En los parques se observaban parejas que hacían más que conversar, y en múltiples revistas femeninas se daban consejos precisos sobre moda, maquillaje, arreglo personal y, sobre todo, lo que implícitamente es el arte de la seducción. También en los años ochenta, algunos estudios hechos por académicos revelaron que había una gran ignorancia sobre sexualidad entre los jóvenes, lo que a veces creaba problemas en el matrimonio. Entonces se publicaron manuales sobre sexo para recién casados cuya intención era más ser prontuarios de higiene que fomentar relaciones sexuales satisfactorias. ${ }^{34}$

A partir de mediados de la década de 1990 la discusión sobre sexualidad se volvió mucho más abierta y proliferaron estudios sobre sexualidad y comportamiento sexual financiados tanto por el gobierno chino como por fundaciones extranjeras, como la encuesta dirigida por Pan Suiming en 1999, que valora los conocimientos de los jóvenes sobre sexo en una situación en que el aumento de casos de enfermedades de transmisión sexual, sobre todo el sida, pusieron en alerta al gobierno chino. Hay que mencionar también la encuesta sobre comportamiento sexual de Liu Dalin, realizada en 1989-1990 y publicada

${ }^{33}$ Ibid., p. 498.

${ }^{34}$ Flora Botton y Romer Cornejo, "Sexualidad en China", Estudios de Asia y África, vol. 24, núm. 3 (80), septiembre-diciembre de 1989, p. 439. 
en $1992 .{ }^{35} \mathrm{Si}$ bien no hay en este momento encuestas e investigaciones amplias sobre actitudes y costumbres sexuales en China en el siglo XXI, hay estudios puntuales y locales que ayudan a vislumbrar algunos aspectos de las actitudes sobre sexualidad en la China actual. ${ }^{36}$ Hasta principios de los años noventa, el sexo premarital era considerado inaceptable, pero desde el principio del cambio de milenio tuvo mayor aceptación. Según entrevistas llevadas a cabo en 2011, más de $90 \%$ tanto de los entrevistados urbanos como de los rurales conocían a personas que habían tenido sexo premarital y, aunque la aprobación dependía de la edad de los entrevistados, muchos lo consideraron como algo "normal" en el contexto de una sociedad cambiante y que sería deseable que fuera el preludio de una estable. ${ }^{37}$ Hasta 1980, la cohabitación de una pareja era mínima y se puede explicar, además de atribuirse a consideraciones morales, por la imposibilidad de obtener una vivienda para un soltero o una pareja que no estaba casada. Sin embargo, desde 1980 la cohabitación aumentó rápidamente y de $5 \%$ en los años ochenta, fue de $12.1 \%$ en los noventa y, después del 2000, llegó a 32.6\%. Hay una estrecha correlación entre el nivel educativo y la cohabitación: entre parejas con educación superior es de 25 por ciento. ${ }^{38}$

Las relaciones extramaritales fueron muy criticadas en China y antes de los años ochenta la parte agraviada podía recurrir a la unidad de trabajo del cónyuge culpable y denunciarlo; las consecuencias podían ir de la crítica pública a la pérdida de prestaciones y hasta del trabajo. ${ }^{39}$ Como se indicó, las relaciones extramatrimoniales aumentaron en épocas recientes, pero la opinión pública, en áreas tanto urbanas como rurales, es negativa y las considera inmorales, destructoras de la familia y dañinas para los hijos. ${ }^{40}$ Aunque la Ley de Matrimonio de 2001

${ }^{35}$ En 1997 fue publicada en inglés. Véase Liu Dalin, Man Lun Ng, Li Ping Zhu y Edwin J. Haeberle, Sexual Behavior in Modern China. Report on the Nationwide Survey of 20000 Men and Women, Nueva York, Continuum, 1997.

${ }^{36}$ Véase, por ejemplo, Zheng, Xudong, Chi, Wei, Lu y Hesketh, "Detraditionalisation and Attitudes to Sex...”, op. cit.

${ }^{37}$ Ibid., pp. 501 y 506.

${ }^{38} \mathrm{Xu}$, Jianxin y Xuejun, “Continuity and Change...”, op. cit., pp. 43-44.

${ }^{39}$ Botton y Cornejo, "Sexualidad en China", op. cit., p. 440.

${ }^{40}$ Zheng, Xudong, Chi, Wei, Lu y Hesketh, "Detraditionalisation and Attitudes to Sex...”, op. cit., p. 502. 
prevé situaciones de adulterio y propone medidas de penalización y compensación, estudiosos como la socióloga feminista $\mathrm{Li}$ Yinhe advierten de los peligros de involucrar a las autoridades en asuntos personales, situación que tanto daño había provocado durante la Revolución Cultural. ${ }^{41}$

El matrimonio entre personas del mismo sexo no es aún un tema prioritario para las autoridades chinas. La homosexualidad hasta el 2001 era considerada una enfermedad y, en general, no hay gran aceptación de esta preferencia sexual. Los activistas (que cada día son más numerosos) señalan que hay tres actitudes sobre homosexualidad: ignorancia, ambivalencia $y$, en menor grado, apoyo. ${ }^{42}$ Hay que mencionar, sin embargo, que en enero de 2016 una pareja de homosexuales a la que se le había negado el derecho a casarse llevó su caso ante una corte de Changsha, en la provincia de Hunan. Aunque no ganaron el juicio, el que un juez aceptara el caso fue algo alentador. ${ }^{43}$

\section{Relaciones de género}

En la pareja, en aéreas tanto urbanas como rurales, es el hombre el que tiene mayor poder de decisión, pero la desigualdad de género es menor en las ciudades. En las áreas urbanas penetran ideas más modernas sobre relaciones de género, y los mejores niveles de educación, además de una mayor participación de las mujeres en el trabajo remunerado, las hacen menos vulnerables. ${ }^{44}$

En la familia actual todavía es la mujer la que lleva la mayor carga de trabajo doméstico y cuidado de los hijos, y después de las mujeres, son los abuelos paternos los que asumen este papel. Aún en 2010, más de la mitad de los adultos mayores, sobre todo en áreas rurales, vivían con sus hijos, lo que indica que aún está presente la familia extendida en China. En un sistema

${ }^{41}$ Alford y Shen, "Have you eaten? Have you divorced?", op. cit., p. 12.

${ }^{42}$ Timothy Hildebrandt, "Same-sex Marriage in China? The Strategic Promulgation of a Progressive Policy and its Impact on LGBT Activism", Review of International Studies, vol. 37, núm. 3, julio de 2011, p. 1321.

${ }_{43}$ Tom Phillips, "China Court refuses to allow Gay Marriage in Landmark Case", The Guardian, 13 de abril de 2016.

${ }^{44} \mathrm{Xu}$, Jianxin y Xuejun, “Continuity and Change...”, op. cit., p. 50. 
donde, por un lado, aún no es universal la seguridad social o la pensión, y, por otro, los elevados costos de vivienda obligan a las parejas jóvenes a compartir casa con sus padres, esta convivencia es común..$^{45}$ Aun así, la Ley de Matrimonio de 2001 estipula claramente que es obligación de los hijos mantener a los padres y a los abuelos. Como consecuencia de la política de un solo hijo, el modelo actual de la familia en China es de 4-2-1, es decir, cuatro abuelos, dos padres y un hijo, lo que significa que una pareja tendría a su cargo a cuatro adultos mayores. ${ }^{46}$

Mucho se ha discutido el efecto sobre la sociedad china de las políticas draconianas de población. La política de un solo hijo fomentó, sobre todo en áreas rurales, el maltrato de las mujeres, el infanticidio femenino y la creación de una sociedad en la que los hijos únicos, por un lado, reciben una atención desmesurada de padres y abuelos, pero, por el otro, crecen sin un entorno familiar. Estos hijos únicos, al casarse, tendrán la responsabilidad de apoyar a cuatro adultos mayores. La Ley de 2001 reconoce que la mayor carga en cuanto a planificación familiar y sus consecuencias negativas recae sobre las mujeres, e insiste en que las políticas de población deben ir acompañadas de políticas que ayuden a elevar el estatus de las mujeres y ofrezcan mayores oportunidades de educación, empleo y salud; sin embargo, todavía no se percibe que se hayan discutido en China derechos reproductivos individuales. ${ }^{47}$ En la actualidad, se han hecho varias revisiones a la política de un solo hijo. En noviembre de 2013, el gobierno chino anunció que permitiría tener dos hijos si uno de los padres era hijo único. En octubre de 2015, se anunció que todas las parejas podían tener hasta dos hijos.

La privatización de la vivienda en 1998 tuvo consecuencias sobre el derecho de las mujeres a la propiedad, porque la mayor parte de las posesiones residenciales pertenecen a los hombres. El costo de la vivienda actual hace muy difícil que una pareja joven pueda adquirirla sin ayuda de los padres, quienes gene-

${ }^{45}$ Ibid., p. 49.

${ }^{46}$ Flora Botton, “¿Qué hacer con los viejos? El problema del envejecimiento en China”, Estudios de Asia y África, vol. 47, núm. 2 (148), mayo-agosto de 2012, pp. 225227.

${ }^{47}$ Palmer, “Transforming Family Law in post-Deng China”, op. cit., pp. 687-690. 
ralmente están dispuestos a ayudar a un hijo y no a una hija, y la propiedad queda registrada a nombre de éste. Aunque la vivienda fuera comprada por la pareja, con frecuencia las escrituras quedan a nombre del marido y no reflejan la contribución de la esposa en pagos de hipotecas o en la manutención del hogar. Así, en caso de divorcio, la mujer está en desventaja en cuanto al reparto de los bienes comunes. ${ }^{48}$

\section{Educación, trabajo y matrimonio}

Según indican algunos estudiosos, durante la época temprana posrevolucionaria, y sobre todo durante la Revolución Cultural, el nivel de educación no era un factor primordial en la búsqueda de pareja. Lo que más importaba era el origen familiar, la membresía al Partido Comunista, tener una residencia urbana, etcétera. Después de las reformas económicas, el nivel de educación se volvió muy importante y señaló un regreso a los valores tradicionales prerrevolucionarios, pero, en la situación actual, las mujeres también quieren educarse. ${ }^{49} \mathrm{Si}$ una buena educación les ofrece a los hombres mejores oportunidades para encontrar pareja, con las mujeres sucede lo contrario. Los hombres comúnmente se casan antes de los treinta y las mujeres antes de los veinticinco años, pero las que hacen una carrera son más maduras, tienen buenos trabajos, independencia económica y mayores exigencias en cuanto a una pareja. ${ }^{50}$ Este fenómeno de mujeres solteras llamadas sheng nu (solteronas) ha llamado la atención de las autoridades chinas, que realizan campañas mediáticas para convencer a las mujeres de que reduzcan sus ambiciones y exigencias. Las campañas se llevan a cabo con notas periodísticas, informes, encuestas, programas de televisión y hasta caricaturas. La misma Federación de Mujeres de

${ }^{48}$ Leta Hong Fisher, Leftover Women: The Resurgence of Gender Inequality in China, Londres, Zed Books, 2014, pp. 75-76 y 83-84; Palmer, “Transforming Family Law in post-Deng China”, op. cit., p. 685.

${ }^{49}$ Véase Xu, Jianxin y Xuejun, “Continuity and Change...”, op. cit., p. 42.

${ }^{50}$ Christina Larson, “The Startling Plight of China's Leftover Ladies”, Foreign Policy, núm. 193, mayo-junio de 2012, pp. 95-96; Davin, "Marriage Migration in China and East Asia”, op. cit., pp. 89-91. 
China, órgano del Partido Comunista, se ha involucrado en los esfuerzos para estigmatizar a las sheng nu. En 2014 Leta Hong Fisher publicó un libro en el que estudia la situación de las sheng nu como indicador del resurgimiento de la desigualdad de género en China. Para la autora, esta campaña que menosprecia los logros de las mujeres en el ámbito académico y laboral está diseñada para, entre otras metas, promover el matrimonio de mujeres "de calidad". ${ }^{51}$

La incorporación al trabajo remunerado a partir de 1949 fue fundamental para elevar el estatus de las mujeres, a las que se invitó a participar en la construcción del socialismo en pie de igualdad, como lo indicaba el famoso lema de Mao: "Las mujeres sostienen la mitad del cielo”. Aun así, la mayoría de las tareas domésticas seguía recayendo en las mujeres, pero había un sentimiento de participación y de dignidad, amén de que el empleo de ellas era indispensable para la economía del hogar. A partir de principios de los años noventa, con las reformas económicas, muchas empresas chicas y medianas fueron privatizadas, y varias empresas del Estado, cuyo manejo era ineficiente y su rendimiento mediocre, paulatinamente fueron cerradas. Esto provocó despidos masivos, y de 1995 a 2002 perdieron su trabajo 45 millones de trabajadores. La proporción de mujeres despedidas es mayor que la de los hombres y, según estadísticas de 2010, la participación de las mujeres urbanas en el mercado laboral, en veinte años, cayó de 77.4 a 68\%. Muchas mujeres fueron obligadas a "regresar al hogar" ${ }^{52}$

Una investigación de 2010 estudia el efecto que el empleo de las mujeres tiene en la calidad del matrimonio. Los resultados indicaron que cuando ellas estaban desempleadas había mayores tensiones en las parejas, y cuando tenían empleo había mayor armonía. Esto se debe, por un lado, a la disminución de recursos económicos en el hogar y, por el otro, a la actitud de rencor y de cierto desprecio de los esposos hacia sus mujeres por su incapacidad de contribuir a la economía doméstica. ${ }^{53}$

${ }^{51}$ Hong Fisher, Leftover Women, op. cit., pp. 15-25.

${ }^{52}$ Ibid., pp. 36-38.

${ }^{53} \mathrm{Hu}$ Xiaohe, Xuhui Zeng, Li Zheng y Christy Flatt, "How does Wives' Unemployment Affect Marriage in Reforming Urban China”, Journal of Comparative Family Studies, vol. 41, núm. 5, otoño de 2010, pp. 730-731. 


\section{Conclusiones}

¿Cuál es la situación del matrimonio en China en la actualidad? En muchos aspectos, la familia ha adoptado formas más modernas gracias a la disminución de la injerencia del Estado en la vida privada, al desarrollo económico y a actitudes más individualistas de los jóvenes. Sin embargo, paradójicamente, al disminuir la presión que imponía el modelo del Estado socialista, surgieron patrones de conducta de la familia tradicional. En contraste con la austeridad pregonada después de la Revolución, se volvió a las ceremonias costosas, a las dotes y a la compra de mujeres en el ámbito rural. Al tener más dinero, muchos hombres prefieren que sus esposas no trabajen y pueden tener amantes a las cuales mantienen. En la nueva economía las mujeres están en desventaja en cuanto a oportunidades de trabajo y derecho a poseer propiedades adquiridas durante el matrimonio. Finalmente, la falta de apoyos del Estado para el cuidado de los hijos obliga a convivir con los padres, lo que transforma a la familia nuclear en familia extendida.

Dirección institucional de la autora:

Centro de Estudios de Asia y África

El Colegio de México

Carretera Picacho Ajusco 20

Ampliación Fuentes del Pedregal

14110, Ciudad de México

\section{Bibliografía}

Alford, William P. y Shen Yuanyuan, "Have you eaten? Have you divorced? Debating the Meaning of Freedom in Marriage in China”, en William Kirby (ed.), Ideas of Freedom in the Chinese World, Stanford, Stanford University Press, 2003, pp. 1-33. [< https:// wcfia.harvard.edu/publications/have-you-eaten-have-you-divorced-debating-meaning-freedom-marriage-china $>$, consultado en noviembre de 2016.]

BотTоn, Flora, "Algunas consideraciones sobre las relaciones intrafamiliares y las redes de apoyo en la China actual”, Estudios 
de Asia y África, vol. 51, núm. 3 (161), septiembre-diciembre de 2016, pp. 511-530.

BotTon, Flora, "Cambio social y cultura", en Romer Cornejo (coord.), China. Radiografía de una potencia en ascenso, México, El Colegio de México, 2008, pp. 121-206.

BotTON, Flora, "El amor es cosa seria: el discurso oficial sobre el amor en China (1949-1979)", Estudios de Asia y África, vol. 29, núm. 3 (95), septiembre-diciembre de 1994, pp. 385-400.

BotTon, Flora, "La larga marcha hacia la igualdad. Mujer y familia en China", en Taciana Fisac (ed.), Mujeres en China, Madrid, Agencia Española de Cooperación Internacional, 1995, pp. 11-43.

BotTon, Flora, "La sociedad china contemporánea: una visión actual”, en José Luis Estrada, José Luis León y Ricardo Buzo (coords.), China en el siglo XXI. Economía, politica y sociedad de una potencia emergente, México, Universidad Autónoma Metropolitana, 2006, pp. 41-57.

BotTon, Flora, "¿Qué hacer con los viejos? El problema del envejecimiento en China”, Estudios de Asia y África, vol. 47, núm. 2 (148), mayo-agosto de 2012, pp. 219-236.

BotTon, Flora y Romer Cornejo, Bajo un mismo techo. La familia tradicional en China y sus cambios, México, El Colegio de México, 1993.

BotTon, Flora y Romer Cornejo, “Corazones solitarios: los anuncios matrimoniales y la elección de pareja en China", Estudios de Asia y África, vol. 25, núm. 1 (81), enero-abril de 1990, pp. 83-104.

BotTon, Flora y Romer Cornejo, "Sexualidad en China", Estudios de Asia y África, vol. 24, núm. 3 (80), septiembre-diciembre de 1989, pp. 425-444.

DAvIN, Delia, "Marriage Migration in China and East Asia", Journal of Contemporary China, vol. 16, núm. 50, marzo de 2007, pp. 83-95.

Evans, Harriet, "Matrimonio y familia en China", Revista FEM, vol. 7, núm. 22, abril-mayo de 1982, pp. 5-10.

HildebrandT, Timothy, "Same-sex Marriage in China? The Strategic Promulgation of a Progressive Policy and its Impact on LGBT Activism", Review of International Studies, vol. 37, núm. 3, julio de 2011, pp. 1313-1333.

Hong FincHER, Leta, Leftover Women: The Resurgence of Gender Inequality in China, Londres, Zed Books, 2014.

Hu Xiaohe, Xuhui Zeng, Li Zheng y Christy Flatt, "How does Wives' Unemployment Affect Marriage in Reforming Urban China", Journal of Comparative Family Studies, vol. 41, núm. 5, otoño de 2010, pp. 717-734. 
Larmer, Brook, "The Price of Marriage in China", The New York Times, 9 de marzo de 2013. [ <www.nytimes.com/2013/03/10/ business/in-a-changing-china-new-matchmaking-markets. html >, consultado en diciembre de 2016.]

LARson, Christina, "The Startling Plight of China's Leftover Ladies", Foreign Policy, núm. 193, mayo-junio de 2012, pp. 94-98.

Lawrence, Susan, "Divorce, Chinese Style", Far Eastern Economic Revierw, vol. 164, núm. 11, 15 de marzo de 2001, pp. 64-66.

Li Shuzhuo, Zhang Qunlin, Yang Xueyan e Isabelle Attané, "Male Singlehood, Poverty and Sexuality in Rural China: An Exploratory Survey", Population, vol. 65, núm. 4, 2010, pp. 679-693.

Liu Dalin, Man Lun Ng, Li Ping Zhu y Edwin J. Haeberle, Sexual Behavior in Modern China. Report on the Nationwide Survey of 20000 Men and Women, Nueva York, Continuum, 1997.

LIXIN Colin Xu, Christine Zhen-Wei Qiang y Limin Wang, "The Timing of Marriage in China", Annals of Economics and Finance, vol. 4, núm. 2, noviembre de 2003, pp. 343-357.

Lu Yang, "The Correct Handling of Love, Marriage, and Family Problems", Chinese Sociology and Anthropology, vol. 1, núm. 3, primavera de 1969 , pp. 7-59.

National Center for Education Statistics, "Number of Divorces in China in 2014, by Region", Statista. The Statistics Portal, s.f. [ <www.statista.com/statistics/279451/number-of-divorces-inchina-by-region/ > , consultado en noviembre de 2016.]

National Center for Education Statistics, "Number of Registered Marriages in China from 2004 to 2014 (in Millions)", Statista. The Statistics Portal, s.f. [<www.statista.com/statistics/279445/ number-of-registered-marriages-in-china/ $>$, consultado en noviembre de 2016.]

Palmer, Michael, "Transforming Family Law in post-Deng China: Marriage, Divorce and Reproduction", The China Quarterly, vol. 191, septiembre de 2007, pp. 675-695.

Phillips, Tom, "China Court refuses to allow Gay Marriage in Landmark Case", The Guardian, 13 de abril de 2016. [<www. theguardian.com/world/2016/apr/13/china-court-refuse-gaymarriage-landmark-case $>$, consultado en noviembre de 2016.]

Po Hu T'ung, The Complete Discussions with the White Tiger Hall, intr. y trad. Tjan Tjoe Som, Leiden-Boston, E. J. Brill, 1952, vol. 1, pp. 232-233.

Pochagina, Olga, "New Version of the PRC Law on Marriage", Far Eastern Affairs, vol. 30, núm. 4, octubre-diciembre de 2002, pp. 25-38. 
Poston, Dudley L. y Karen S. Glover, “Too Many Males: Marriage Market Implications of Gender Imbalances in China", Genus, vol. 61, núm. 2, abril-junio de 2005, pp. 119-140.

Quanbao Jiang, Yanping Zhang y Jesús J. Sánchez-Barricarte, "Marriage Expenses in Rural China", The China Review, vol. 15, núm. 1, primavera de 2015, pp. 207-236.

The Li Ki, trad. James Legge, en F. Max Müller (ed.), The Sacred Books of the East, vol. 28, Delhi, Motilal Banarsidass, 1966.

Wong Wei Mei, "Finding 'Love' in China: An Overview of Chinese Marriage Markets (BaiFaXiangQin)", Inquiries Journal, vol. 6, núm. 12, 2014. [<http://www.inquiriesjournal.com/articles/946/finding-love-in-china-an-overview-of-chinese-marriagemarkets-baifaxiangqin >, consultado en octubre de 2016.]

Xu Qi, Jianxin Li y Xuejun Yu, "Continuity and Change in Chinese Marriage and the Family: Evidence from the CFPs", Chinese Sociological Revierw, vol. 47, núm. 1, 2014, pp. 30-56.

ZHANG Xuejun, "Amendment of the Marriage Law in China", International Journal of Law, Policy and the Family, vol. 16, núm. 3, 1 de diciembre de 2002, pp. 399-409.

Zheng Weijun, Xudong Zhou, Chi Zhou, Wei Liu, Lu Li y Therese Hesketh, "Detraditionalisation and Attitudes to Sex Outside Marriage in China", Culture, Health E Sexuality, vol. 13, núm. 5, mayo de 2011, pp. 497-511.

ZHENG Zhenzhen, "Interventions to balance Sex Ratio at Birth in Rural China”, en Isabelle Attané y Christophe Z. Guilmoto (eds.), Watering the Neighbor's Garden, París, Committee for International Cooperation in National Research in Demography, 2007, pp. 327-346. 


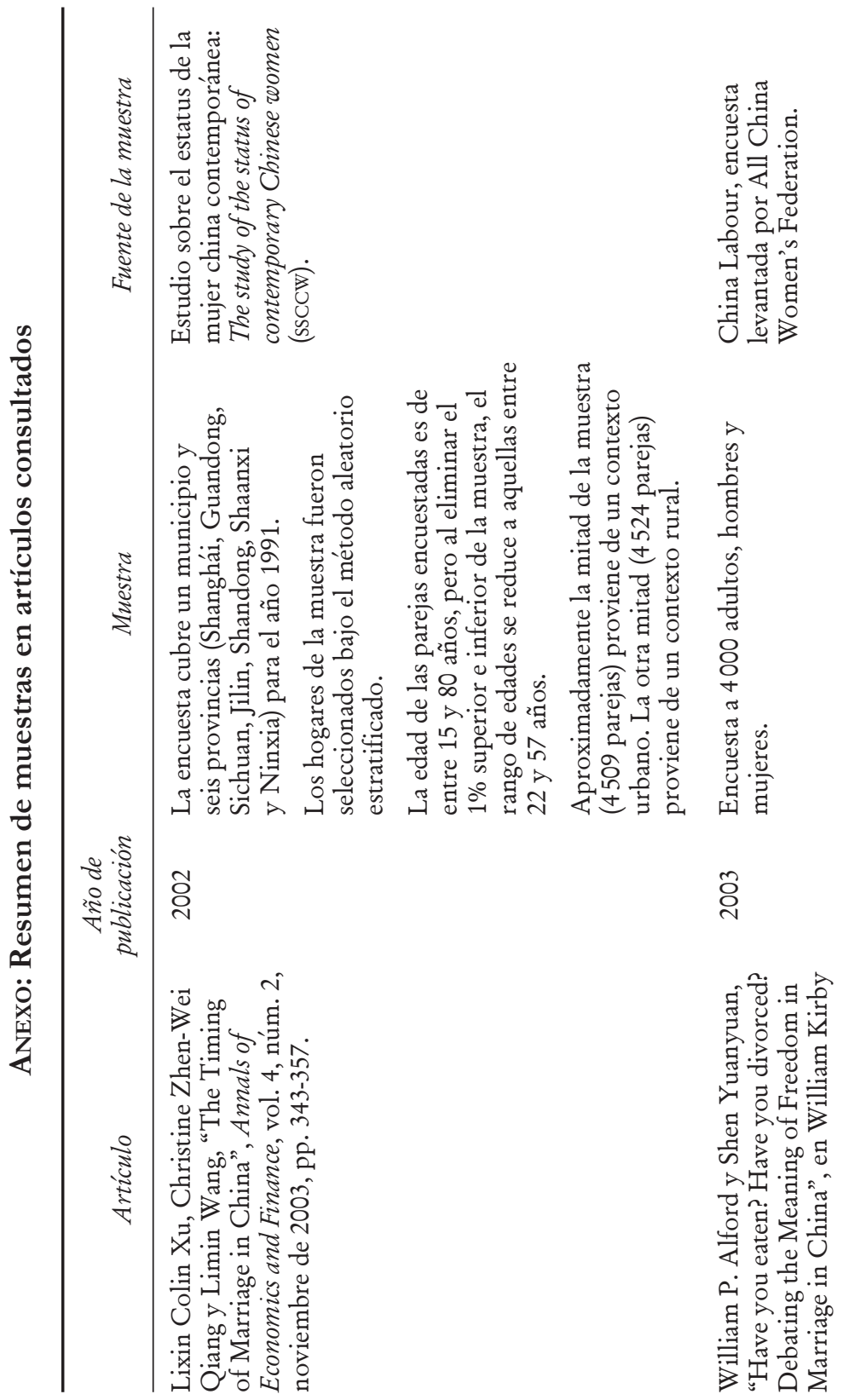




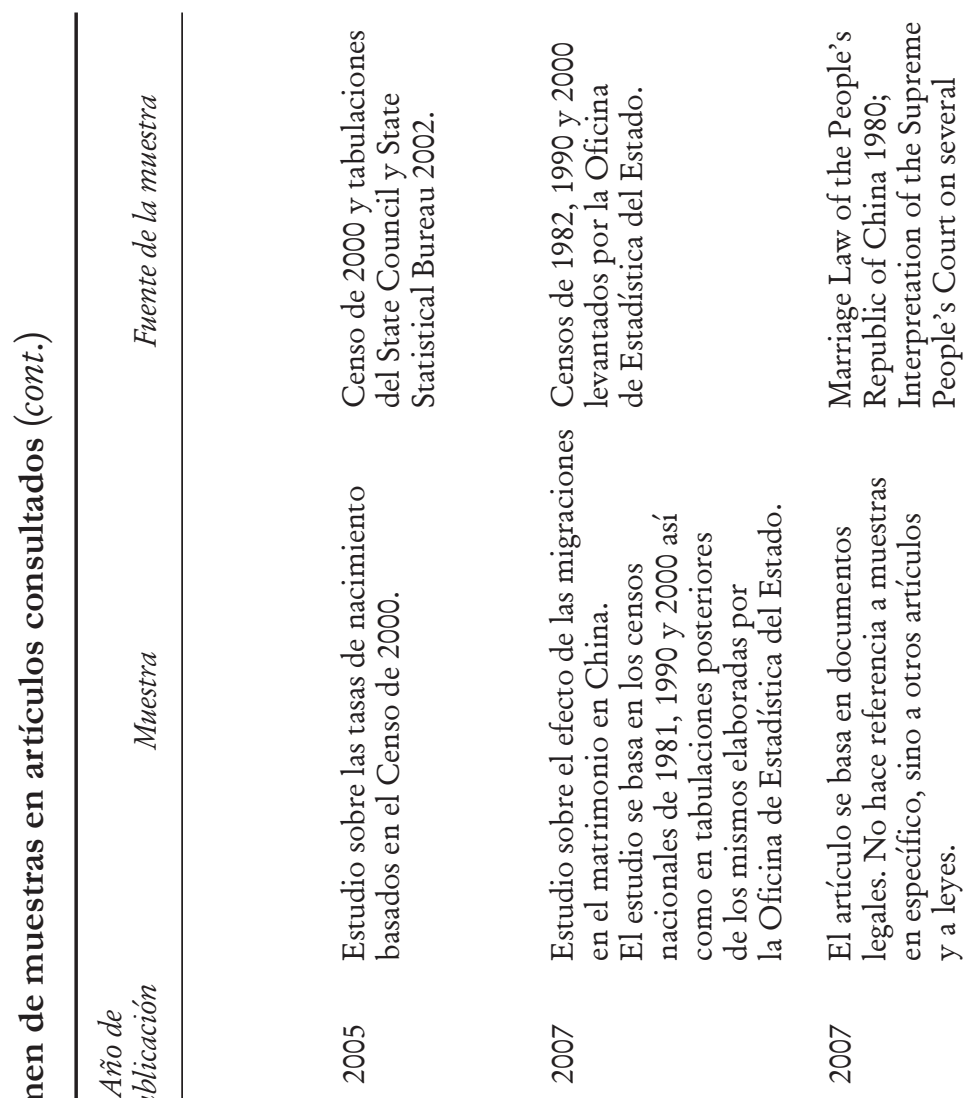

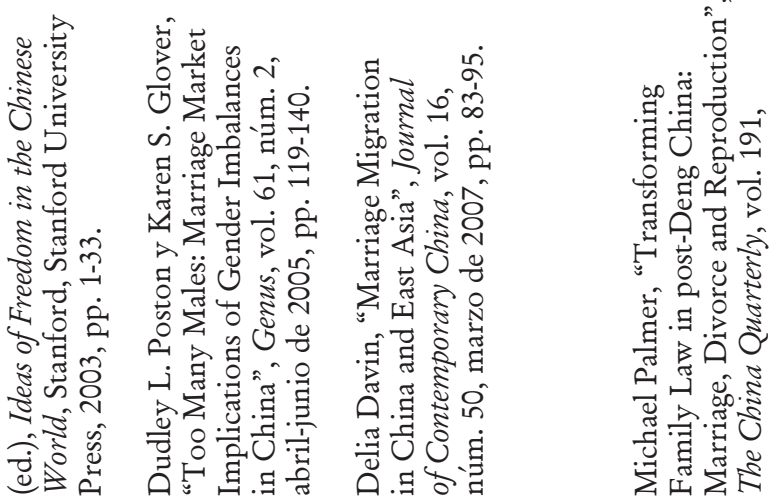




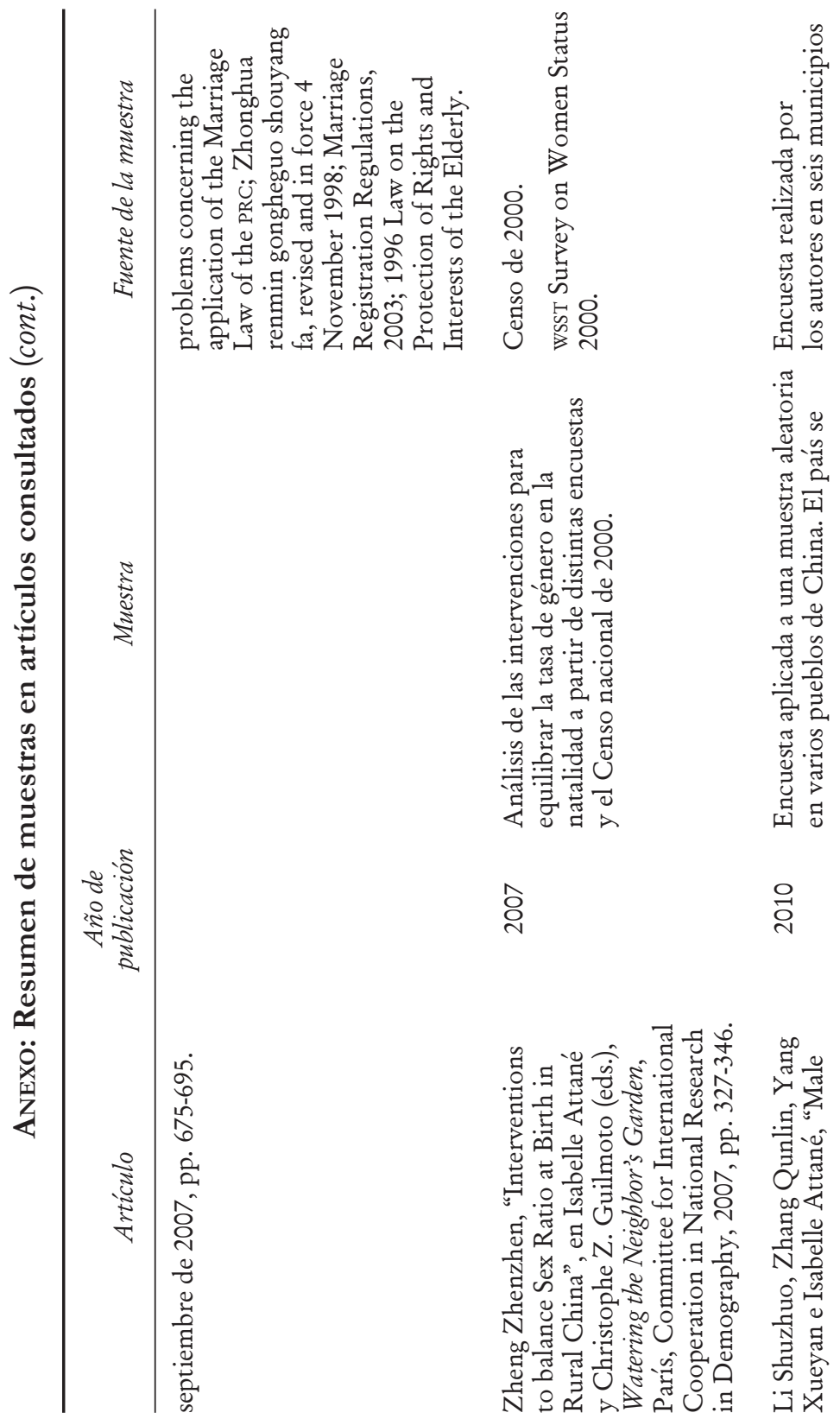




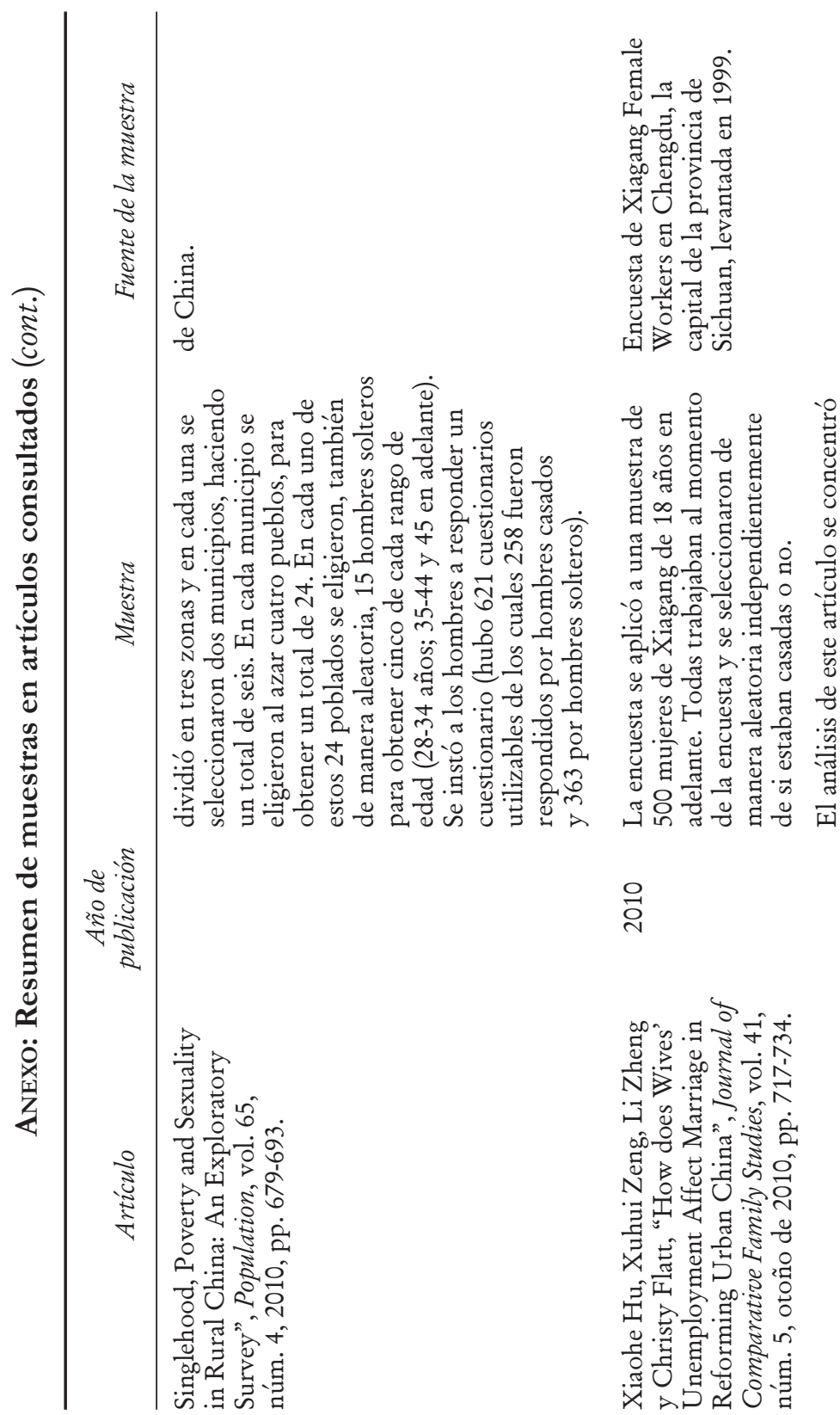




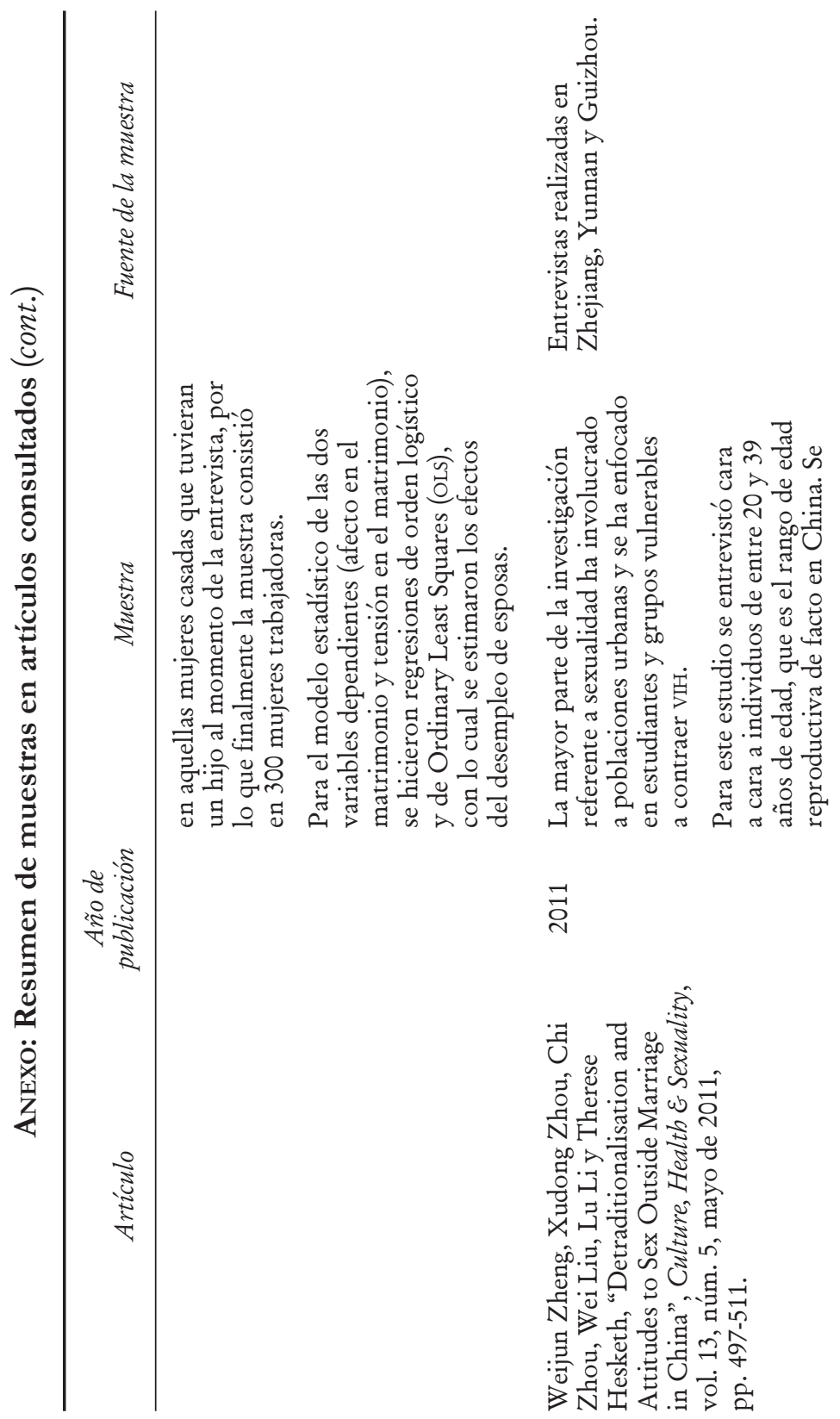




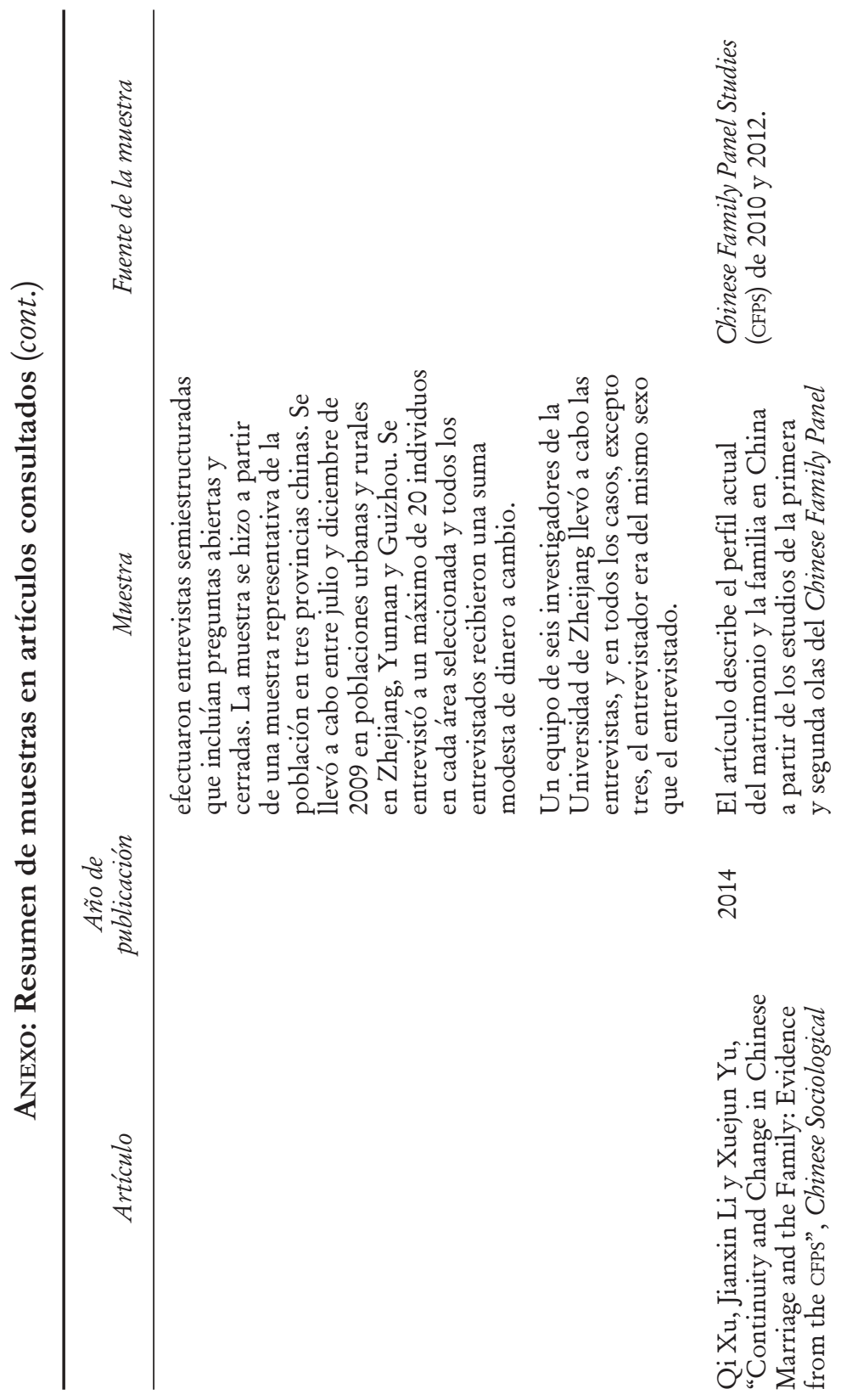




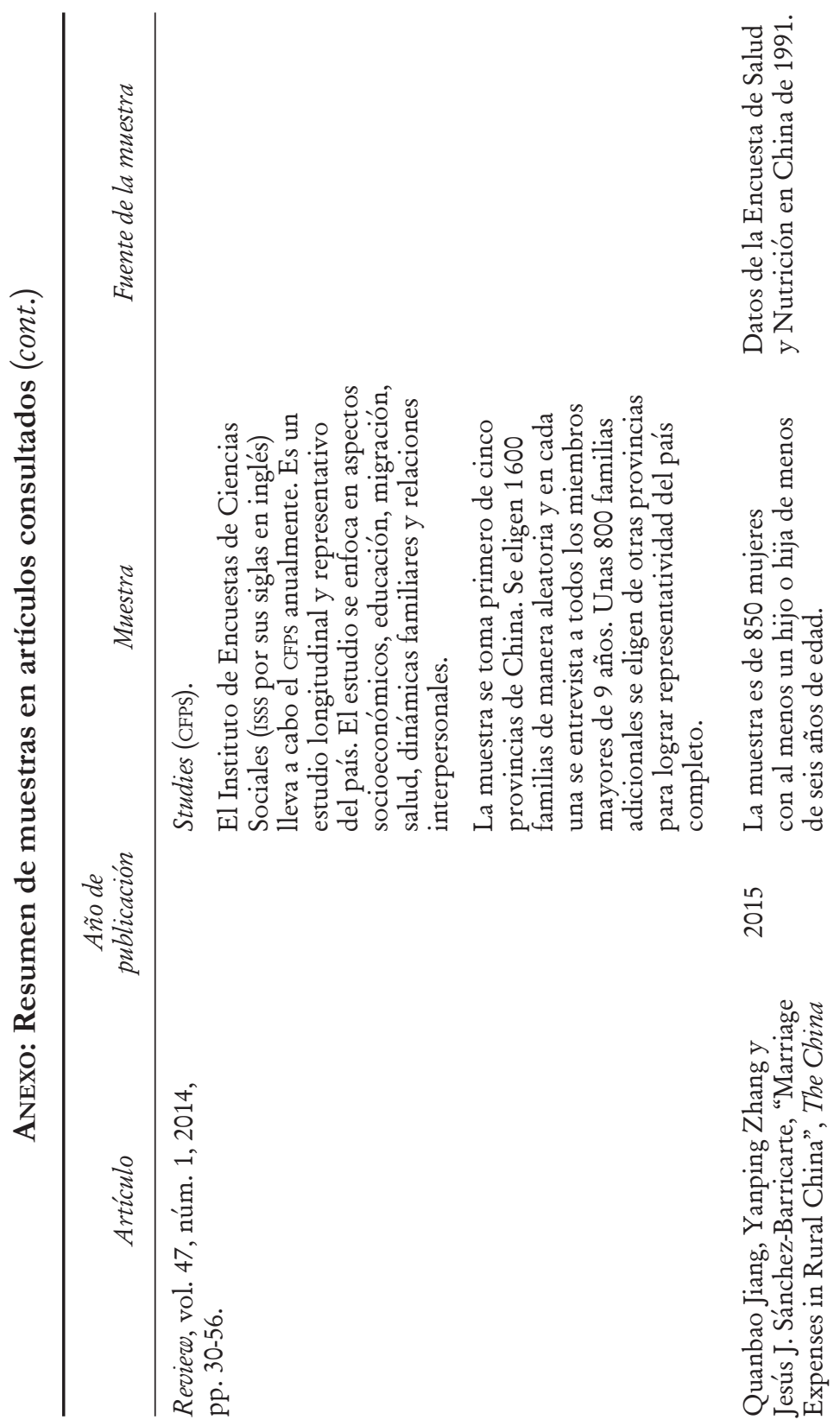




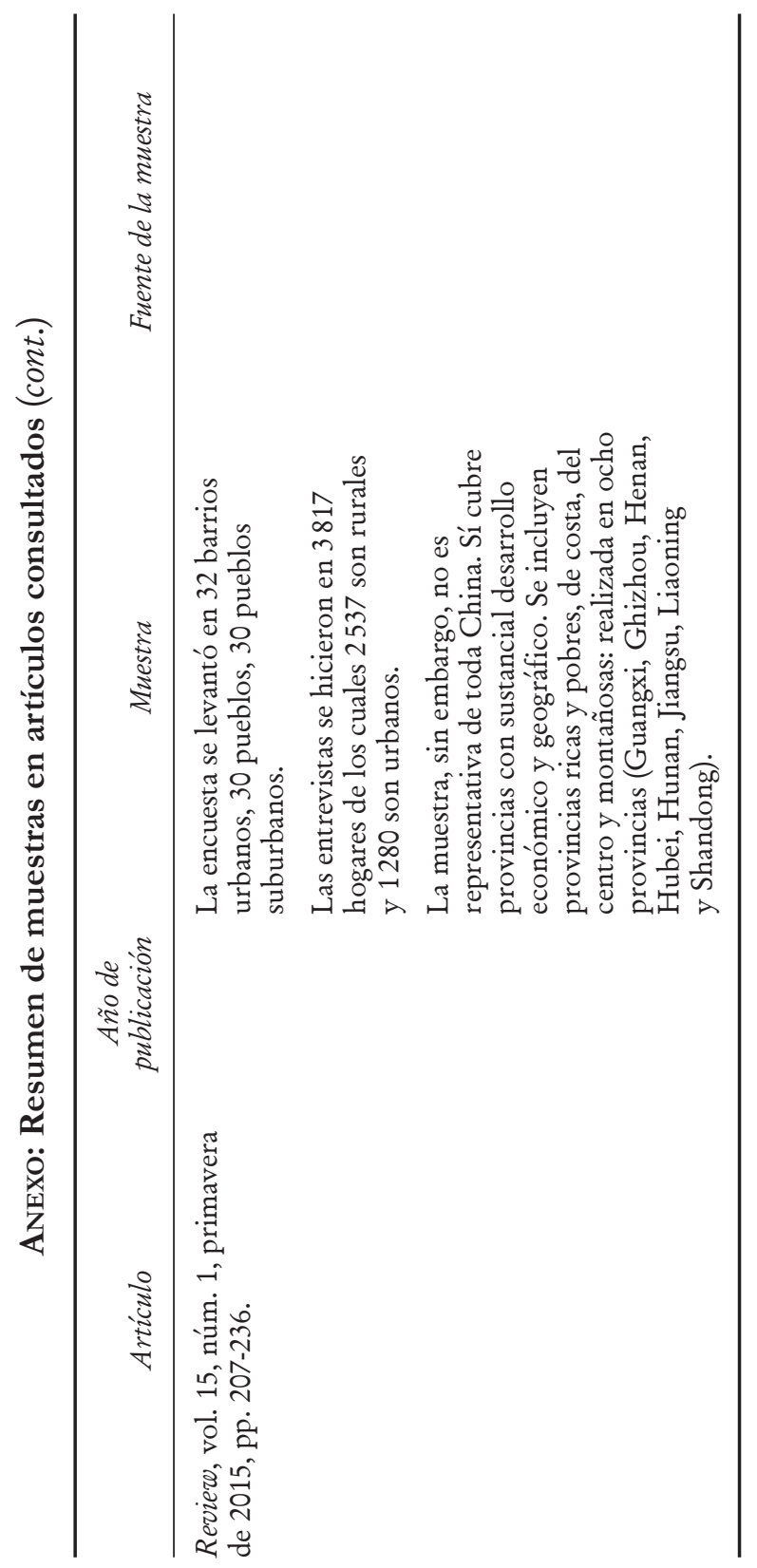

